\title{
Exploring Issues of National Identity, Ideology and Diversity in Contemporary Canadian Picture Books
}

\author{
Ingrid Johnston, Joyce Bainbridge, Farha Shariff
}

Picture books are one of the first points of contact for children to interact with verbal and visual representations of national identity and they can be an ongoing medium for literary engagement throughout children's schooling. Contemporary picture books appeal to a range of readers, and offer innovative possibilities for exploring questions of representation, identity, culture, race, class, and power. In complex interactions between text and illustrations, picture books take up particular ideological positions and articulate varying understandings of national identity, multiculturalism, and cultural difference (Stephens 1992). As Andrea McKenzie (2003) suggests, picture books can have a significant impact in shaping how children understand the world around them: 'Illustrations are not merely adjuncts to the text, but can, as well known illustrations of children's text demonstrate, influence the development of attitudes and values: text and illustrations dynamically interact, each shaping future narratives, both in pictures and in word' (McKenzie 2003,pp.201-202). Similarly, Perry Nodelman reminds us of the ideological basis of illustrations in such texts: 'Whether we are conscious of it or not, illustrations always convey information, not just about what things look like, but how we should understand and what we should feel about the things depicted' (Nodelman 1999, p.6). In this way, picture books have the potential to articulate varying understandings of Canadian identity, offering a double form of representation in the liminal spaces between words and images. They may promote a cohesive and exclusionary view of national identity that can marginalize or exclude diverse immigrant and Aboriginal perspectives, or serve as a counter-articulation to such notions of a homogenous sense of nation.

As teacher educators, we are particularly interested in the potential of contemporary Canadian picture books to engage teachers and students in complex reflections on questions of national identity, ideology, representation, and diversity. Erin Manning explains that identity, as the basis for national unity, 'relies on a simplified notion of culture that ignores the disjunctions and contradictions within historical and social (trans)formations' (Manning 2003, p.62). Neither identity, subject- formation, nor culture can exist in an ahistorical political realm, but each is always subject to transformation and renegotiation. Encounters with difference, even in seemingly simple texts such as picture books, challenge readers to come face to face with disruptions to their socially-constructed subject positions as well as their fears and uncertainties of otherness. Such encounters may challenge readers' sense of self and their taken-for-granted views about contemporary notions of Canadian multiculturalism.

Encounters that disturb a reader's sense of self characterise what Deborah Britzman (1991) calls 'difficultknowledge', a concept meant to signify both representations of social traumas in curriculum and the individual's encounters with these traumas in pedagogical contexts. According to, students come into the teaching context with takenfor-granted views about the world, which she refers to as 'lovely knowledge'. 'Difficult knowledge' disrupts these assumptions and may cause ruptures in students' 'lovely knowledge' of how multiculturalism functions in Canadian society.

We drew upon these post-structural notions of identity in developing our project, a three-year study conducted as descriptive case studies (Stake 1995, Merriam 1998) with English language arts preservice teachers in five Canadian provinces. In the research, we intended to challenge preservice teachers to negotiate their own sense of national identity and to examine their views of otherness through reading and responding to a range of contemporary Canadian picture books. This study is particularly topical, given a growing disparity between the backgrounds of beginning teachers and the students in their classrooms. While the public schools of most Canadian urban centres are microcosms of diversity, with increasing numbers of recent immigrants from non-Western countries and a growing Aboriginal student population, Canada's teaching population remains predominantly white, with a majority of practicing and preservice teachers coming from European backgrounds (Beynon 2004, Carson \& Johnston 2002). Many of these preservice teachers, while professing support for Canada's official multiculturalism policies and for equitable teaching strategies, express concerns about working in diverse classroom contexts and have little experience of questioning stereotypes of Canada's immigrant and Aboriginal peoples in the texts they read and teach (Richardson et al 2003, Wiltse 2005). 
At the start of the study, in collaborative discussions, researchers at each of the five sites made joint decisions about which Canadian multicultural picture books to select for the study. Text selections were based on the following criteria:

- Published in Canada since 1990

- From a variety of regions in Canada

- Authors/Illustrators from a range of ethnocultural backgrounds

- Books that present differing viewpoints on what it means to be Canadian

- Books that illuminate a variety of perspectives on "diversity" in Canadian society

- Books from English, French, Heritage language and Aboriginal language traditions

For year one of the study, we selected sixty-eight picture books that met these criteria and introduced the books to preservice teachers enrolled in literacy courses at each of the five sites. In each site, participants were engaged in a threehour workshop which provided them with opportunities to consider the evolution and potential of multicultural picture books; explore the interplay between texts and visual representations; read and respond to picture books.

We provided the preservice teachers with a brief historical overview of Canadian multiculturalism and the influence of federal policies on the changing literary scene. We explained that Canada was the first country in the world to adopt an official Multiculturalism Policy in 1971. This policy recognised that all Canadian men and women have the same rights, freedoms, and responsibilities. Over the years, the policy has been lauded for promoting equality and inter-cultural understanding, and for working towards eliminating racism and discrimination in Canada. It has encouraged Canadian institutions to be more reflective of the multicultural face of our country. Despite the introduction of these policies, Canadian picture books published during the 1970s still tended to privilege a dominant white Eurocentric perspective, with minority viewpoints and experiences ignored or relegated to the margin. It took until the mid 1980 s for official notions of 'cultural diversity' to begin making an impact on the Canadian literary scene with writers and illustrators such as George Littlechild (Ahenakew 1988), Paul Yee (1989), and Michael Kusugak (1990) exploring narrative and artistic traditions outside the white, western mainstream.

Many writers and illustrators of Canadian children's books during the 1990s and into the start of the 21 st century focused their attention on depicting an idealised view of Canada as a symbol of multicultural harmony and tolerance towards a growing immigrant and Aboriginal population. In the workshop we showed how a number of Canadian literary theorists, writers, and artists have critiqued simplistic notions of plurality that underpin official multiculturalism. Liberal multiculturalism has tended to focus on issues of culture, rather than on more contentious concepts of ethnicity, race, and language, encouraging a view of Canada as a cohesive cultural mosaic. This concept of multiculturalism has evoked a double-edged critique from writers who see the mosaic as potentially exclusivist and essentialist. Bharati Mukherjee (1997) for example, has complained that Canada is a country that officially and proudly resists cultural fusion. She suggests that for all its rhetoric about a cultural 'mosaic', Canada refuses to renovate its national self-image to include its changing complexion. For Mukherjee, Canada is a New World country with Old World concepts of a fixed, exclusivist national identity.

Manning (2003) echoes similar sentiments when she argues that 'multiculturalism follows the trajectory of the nation's white supremacist agenda, positing whiteness as an invisible norm by which other ethnicities are judged and categorized' (p.87). She elaborates this stance by explaining that

the discourse of multiculturalism in Canada fails to interrogate the dominant regimes of the nation's discursivity; thus the social and cultural practices of the nation continue to be inscribed through racist, classist, sexist, and nationalist agendas that falsely promise that every ethnic group can reap the economic, cultural, and national benefits of state sovereignty.

(p.87) 
These critiques of official multiculturalism have been taken up by a number of writers and illustrators in the $21 \mathrm{st}$ century who are challenging notions of a metanarrative in the Canadian literary field (Bannerji 2000) and helping to re-define Canada's unified story as a postmodern bricolage of competing traditions, histories, re-tellings, and reimaginings. In the past few years, writers and illustrators of European descent, such as Kevin Major (2000), immigrant and second generation Canadians such as Chieri Uegaki (2003), and Aboriginal writers such as Tomson Highway (2001) have produced picture books with the potential to disrupt any homogeneous notion of Canadian identity and to value what Homi Bhabha terms 'the migrant culture of the in-between' (Bhabha 1994, p.224).

Following this historical overview, researchers presented a whole-class critical reading and viewing of the picture book Josepha: A Prairie boy's story (McGugan \& Kimber 1994) which relates the story of a fourteen-year-old Eastern European immigrant to Western Canada in the early 1900s. This picture book won Canada's Governor General's Award for Illustration in 1994 and depicts both visually and textually the tensions inherent in the school/home life of an immigrant during that period of time. Suffering linguistic and racial discrimination in his Canadian school, Josepha makes the decision to leave school to work for a dollar a day bagging grain on a neighbouring farm. In this way, Josepha can be a man and help to support his impoverished family. This reading provided the basis for a discussion of the complex interactions between text and illustration and the ways in which picture books can articulate varying understandings of national identity, multiculturalism, and difference.

We then invited participants to spend time in small groups during the course of two class periods to read, view, and discuss picture books from the collection. Following the workshop, we surveyed the preservice teachers, requesting demographic information on their family backgrounds and home language(s), asking about their responses to the picture books and about their understandings of issues of Canadian identity, representation, and stereotyping in relation to the texts. Questions included:
- What are the words and images that best illustrate what 'Canadian Identity' means in the books you've looked at?

- How would you describe 'Canadian Identity' as it is presented in the picture books you read in the workshop?

- In reference to the picture books that you have seen in the workshop, did any of the representations of people or characters seem stereotypical?

- What criteria have you used (or do you plan to use) in the thoughtful selection of classroom literary texts and curriculum materials?

Follow-up audio-taped interviews and small group discussions with a small number of the preservice teachers explored these issues in more depth, and considered the potential of contemporary Canadian multicultural picture books for teaching and curriculum development. The survey results, transcripts, and notes of interviews were analysed qualitatively for emerging themes, focusing on questions of national identity formation as represented in the picture books, participants' own understandings of what it means to them to be Canadian', and the significance of these understandings for their own teaching.

In this article, we focus on year-one findings from one site of the study in the Western Canadian province of Alberta. At our university, with the largest teacher education program in the country, we invited research participants who were enrolled as generalists in the 'elementary-route' of the Bachelor of Education program, and those in the "secondaryroute' with a minor or major in English language arts. Our demographic survey data revealed that the overwhelming majority of these preservice teacher participants were born in Canada, were of European ancestry, and spoke English as their first language. Of the 90 volunteer respondents to the survey, 84 were born in Canada and nine of these indicated they had Aboriginal ancestry. 82 students spoke English as their first language and seven students indicated their first language was German, Cantonese, Polish, Italian, Punjabi, or French. These statistics are reflective of the largely white, European, English-speaking population of teacher education students in Alberta. 
Participants' responses to reading the picture books as indicated in the survey illuminate their particular notions of what it means to be Canadian; their superficial understandings of Canadian multiculturalism; their confusions about and insights into stereotyping in the picture books; and their pedagogical concerns about potentially controversial aspects of diversity in several of the books. We were interested to note that for many of the preservice students in our Faculty, Canadian identity was inherently linked to the place where they lived or grew up. Students drew strong connections with the books they selected to discuss notions of 'the land'. One student said:

\section{Ireally liked the If You're Not from the Prairie book, but again, that was my connection to the land...It really spoke to me about people that really feel that connection to the land, that's important to them and it's something that matters where you go and where you are and that people that have that really strong sense of place in relation to where they've grown up and that it is the best place to be. It made me want to write about where I'm from.}

If You're Not From the Prairie (Bouchard 1993) calls nostalgically on the remembered beauty and tranquility of growing up on the Canadian prairie. The illustrations by Henry Ripplinger depict wide skies, pure white snow, deep golden grain, and towering wooden grain elevators beside the ever-present railway track. In this book, time stands still as children walk along country trails, play with friends and family in the snow, and travel on the school bus. It is significant, that in contrast to Bouchard's later picture books which focus more on the experiences of Aboriginal Canadians, the images in If You're Not from the Prairie represent only inhabitants of European background. Respondents in the study appeared to articulate their sense of comfort with this white landscape'. As Manning (2003) reminds us, art represented in this way 'offers a primarily linear rendition of space, inviting us to enter into an apparently coherent construction of the Canadian landscape' (p.14).

Several other preservice teachers in the study also expressed interest in texts that reflected a strong affiliation to the local physical landscape and the climate of their own region:
To me, Canadian identity really talks to me about landscape... I feel people in Canada have a really strong sense of place. And whether that's a city or whether they grew up in a rural area, or whatever province they're from, people seem to really strongly connect with where they grew up.

The quotation above is reminiscent of the focus on land and landscape described by a number of Canadian writers in the previous century. For example, Margaret Atwood's Survival: A Thematic Guide to Canadian Literature (1972) describes the preoccupation of Canadians with images of survival in an often hostile landscape, and Margaret Laurence's well-known essay 'Where the World Began' (1971) speaks evocatively of the powerful influence of the Canadian prairies on her life and writing. We noted that there were few comments from the preservice teachers in the study about familiar landscapes in the picture books that had been transformed by immigration and represented a diversity of cultures and ethnicities. Such a rendition of landscape, Manning explains, 'encourages a chronotopic reading of the landscape, permitting us to engage with the complexities within the discourse of the landscape, while at the same time inciting us to explore a production of locality that challenges the order and orderliness of the nation-state' (p.14). It was clear from their responses that our participants preferred the more linear historical renditions of landscape that focused on their own family memories and personal experiences.

Another theme that emerged from the survey was a focus on what it means to be Canadian in a multicultural society. Many participants discussed issues of diversity, respect, and freedom in relation to Canadian identity:

Being Canadian means freedom to have your own identity without being judged and a freedom to share and practice your own traditions and beliefs. Being a Canadian to me is being proud of our country, heritage and background. It's also being tolerant and aware of other cultures and backgrounds within Canada.

These comments are illustrative of the views of many preservice teachers in the study, reflecting the perceived inherent value of Canada's official multiculturalism. Yet several of the books on which they focused present idealised 
portrayals ofCanada containing stereotypes and unrealistic images of contemporary Canadian life. No Two Snowflakes (Fitch 2001) describes Canada in terms of the stereotypical markers: ice hockey, snowball fights, sledding, building snow forts, and crunching through the deep winter snow. Other books the preservice teachers focused on included $M$ is for Maple(Ulmer 2001), From Far and Wide(BannatyneCugnet 2000) and A Big City ABC (Moak 2002), each of which views Canadian identity through the lens of official multiculturalism, with its promotion of Canada as accepting and open to immigration and diversity. Yet these books also present stereotypical and historical images of minority groups: blacks as escaping slaves, Aboriginal Canadians wearing feathers and living in the wilderness and, in $M$ is for Maple, depictions of outstanding Canadians who are likely included only because of their 'difference', for example, the first and only female prime minister. Thus the myth of a benign multiculturalism is perpetuated.

Cracks and fissures in this utopia appeared, however, when some participants reflected on how multiculturalism as portrayed in these texts fragmented their 'lovely knowledge' of Canadian identity. Here we see how a number of the preservice teachers isolated themselves from the viewpoints of those people they regard as 'multicultural' and 'other':

We need to remember our culture too, not just focus on others.

People who immigrated to Canada hold different values and beliefs that may be very different from Canadian values of those who call themselves 'Canadian'.

These ambivalences in preservice teachers' perspectives on Canadian identity were also reflected in their responses to issues of stereotyping in the picture books. In our workshop, we had explained to participants that a stereotype is a way of representing and judging other people in fixed, unyielding terms.

Responses to our question about stereotypes moved along a continuum from unaware to insightful. One participant, for example, held the naïve view that all recentlypublished Canadian picture books were free of stereotypes, commenting that 'Modern story books from the last ten years seem not to use stereotypes. I see many stereotypes shattered'. Other respondents failed to see when particular racial cultural, ethnic, religious, gender, and socioeconomic perspectives were presented in a stereotypical manner in the picture books or they misinterpreted parodic postmodern viewpoints as stereotypes. This confusion was particularly evident in responses to A Coyote Columbus Story (King 1990) which re-tells the story of Columbus's arrival in America from an Aboriginal perspective and cleverly interweaves figures from popular culture with the figure of Coyote, the Aboriginal trickster figure, to elucidate new truths about history and about the ongoing forces of colonialism in the continent. As Clare Bradford (2007) explains,

\begin{abstract}
Monkman's visualrepresentations arecharacterized by exaggeration and burlesque. In the illustration where Columbus and his men reach America, the counter-discursive possibilities of caricature are evident: Columbus is depicted in cartoon style, a diminutive figure wearing a ruff, tights, and high-heeled boots, and his associates are shown as shady, cross-dressing adventurers.
\end{abstract}

(Bradford 2007, p.27)

Several preservice teachers, uncertain how to interpret King and Monkman's counter-discursive textual and visual strategies in depicting colonisers and colonised, believed that the author and illustrator had inadvertently resorted to stereotypes in their depictions of the 'discovery' of the 'New World'.

In contrast, one preservice teacher demonstrated an acute awareness of how some picture books represented Aboriginal people in an exotic or traditional manner. She discussed the dangers of having such books in the classroom and spoke about some of the inappropriate cultural messages we may be sending to our students. Reflecting on which books she found troubling, she commented,

I guess not a specific book but in general some of the Aboriginal books depicting children and adults in traditional dress... So that kind of bothered me to have the students who don't know anything about the culture to only identify Aboriginal children as wearing moccasins and feathers and having drums and things of that nature. 
This comment on how several picture books seemed to offer a stereotypical viewpoint that all Aboriginal people live in rural areas and retain their traditional culture was also highlighted by another participant:

\begin{abstract}
I do remember reading a few books that I thought maybe relied overly on generalizations about cultures. And I think that that's probably a really tough thing to address in books, because there's a pretty fine line between stereotyping a culture and completely ignoring a culture altogether. I mean culture obviously does have a pretty strong impact on individuals but at the same time people are individuals. And I can 't think of a specific book but I do remember thinking a little bit like the book portrays that all First Nations people are like this when I'm sure that's not the case.
\end{abstract}

Despite our workshop discussion about issues of stereotyping, we found that the majority of our preservice teachers had difficulty identifying stereotypes in the picture books they read. We speculate that this may be a result of their unfamiliarity with reading books on diversity or because, as white, middle-class Canadians, they have not had direct experience of being the target of a racial or cultural stereotype.

In response to our questions about the potential value of these picture books for their teaching, most participants indicated they had developed some new understanding and appreciation regarding the use of multicultural content in Canadian classrooms:

Honestly, before this course, I didn't really think about the idea of multiculturalism and having diversity in books that I would include. But now that I've taken this course I have realized that I think it would be useful to include a wide range of diversity in the books that I'm using in class. I would try to include First Nations examples.

Another participant agreed that her viewpoints on bringing in multicultural literary materials would be beneficial for all students:

I would like to introduce literature from lots of different cultures into my classroom, kind of regardless of the class structure. But I think you alsoneed to consider the students in your individual class when you are bringing books in. I think if I was teaching in a class with quite a few First Nations students I would maybe try to incorporate more of the First Nations culture. Either way I would want to incorporate it into my classroom because I think all students should know.

It became clear that most preservice teachers in the study were comfortable with the idea of incorporating books into their teaching that deal specifically with issues of race, culture and disability in a non-threatening manner.

There was certainly more resistance among participants to considering the value of books that focused on sexual orientation, or dealt with uncomfortable illnesses such as AIDS. One example was the picture book Mom and Mum are Getting Married (Setterington 2004) with its direct stance on sexual orientation and alternative ways of thinking about family. A number of respondents raised questions about the extent to which these particular texts might be seen as controversial in a school classroom:

There was the one about the child that had two moms. I think it was the, the homosexual family and that one didn't trouble me from a personal basis, but it troubled me in the sense that I'm not sure how I would put that into my classroom and deal with possible backlash. It's something that I would like to discuss and teach and bring to light in my classroom but I'm not sure that it would be appreciated... How could I integrate that type of topic?

Several participants mentioned the potential disapproval of administrators and parents as a disincentive to having these books available in their classrooms and others indicated they would be cautious about bringing books on sexual identity into the classroom without parental consent:

The Mom and Mum one I probably would be very careful with that. I would read it to my children in a heartbeat no problem... But I know there are a lot of families that aren't and I think it would be something that I would need to send a letter home first maybe and say what your opinion is.

The accompanying anxiety this 'difficult knowledge' produced for many of our preservice teachers appeared throughout several of the student narratives. As Pitt and 
Britzman(2003) remind us, 'We are beginning to appreciate just what a pervasive and threatening force it is to imagine the self as influenced by knowledge (p.765).

We were encouraged to note that, despite the complications of 'difficult knowledge' raised by the picture books, a few participants demonstrated that they had moved beyond a fear of controversy about difference and were developing insightful ways of reflecting on their pedagogical responsibilities. One student, for example indicated a rather sophisticated understanding of how teachers view curriculum and the world in which they teach through their own lens:

\section{It's also good to have a lot of teachers kind of do their checklist or something. What should I look for? I will be biased because of my background, so I would like to know what should I look for that would tell me what is important to somebodyelse's cultural viewpoint. What is important in this culture or ethnic background or religion.... I'd want an idea from somebody else's lens, somebody else's view, what they consider is important.}

In reflecting on the findings from the first year of this study, we have come to more in-depth understandings about our preservice teachers' beliefs about national identity, multiculturalism in Canada, and the role of multicultural picture books in the classroom. For most participants in our study, multiculturalism in literature is still regarded as an add-on to curriculum planning and pedagogical practice, rather than as an integral aspect of their teaching. It was apparent that even when they supported the idea of broadening the school canon of literature, most were reluctant to take risks bringing in texts that might create conflict with parents or school administrators. One particular participant highlighted this dilemma with her comments:
Multiculturalism is very important to me and I have confliction about it because I think what I want to do and what is best for me to do in my first year of teaching ... I'm going to be conflicted because social justice, social issues and equality are very much of who I am and it's very important to me to pass that along, but depending on the situation where you're in, that may not be welcomed. So trying to have that represented to children, which

Ifeel is important, but yet doing it in a way and in a manner where I am under a microscope my first years of teaching is going to be difficult.

This preservice teacher articulates some of the most important aspects of this research. By engaging with literary texts that 'represent' Canada's changing landscape, preservice teachers come face to face with their own understandings of what it means to be a Canadian in the 21 st century. The texts, through words and images, evoke responses from these readers that help them to articulate how they view themselves and those who have been positioned as 'other' in Canadian society and the extent to which they are prepared to share these literary representations with the students they will teach.

In common with many new English language arts teachers, our participants have created an idealised image of themselves as being open to diverse literary perspectives and interested in promoting social justice in their classroom with the introduction of a range of texts that address the backgrounds and varied perspectives and interests of their students. Our study reveals the illusory nature of such an image. The cultural psychoanalytic critic, Slavoj Zizek (1989), delineates the competing roles of the imaginary and the symbolic in a person's life. The imaginary becomes the internalised image of an ideal, whole self, situated around the notion of coherence rather than fragmentation, while the symbolic involves the formation of signifiers that are identified with the hegemonic codes of the social world, thereby constraining the self within particular normative roles. Zizek explains further,

Imaginary identification is identification with the image in which we appear likeable to ourselves, with the image representing 'what we would like to be', and symbolic identification, identification with the very place from where we are being observed, from where we look at ourselves so that we appear to ourselves likeable, worthy of love (Zizek 1989, p.105).

Our student teachers, having created for themselves this image of an ideal teacher living in an ideal multicultural country, came to the study with this 'lovely knowledge' intact, only to be confronted with the 'difficult knowledge' of the 'other' in Canada that was represented in the picture 
books they read. This disruption to their sense of self was made even more complex as they reflected on their roles as teachers introducing some of the more 'controversial' texts into classrooms already embedded within the normative social codes of schooling. We believe that for many of these preservice teachers, our study provided an opportunity for them to begin their journey towards a more dialogic understanding of themselves and 'other'. As Manning (2003) evocatively explains,

\section{Reading inaugurates a politics-under-deconstruc- tion. Reading is an interpretive gesture always to come that challenges my subjectivity-in-process... Tracing a path to an opening, reading can also be formulated as a proposal for an encounter with the other. The text is the other to whom I turn not for comprehension, but for the challenge of exposing my own difference.}

(p.151)

The study described in this article is funded by a threeyear grant from the Social Sciences and Humanities Research Council of Canada. Co-researchers in the study are Lynne Wiltse (Thompson Rivers University), Angela Ward (University of Saskatchewan), Mary-Clare Courtland (Lakehead University), Roberta Hammett (Memorial University).

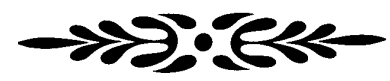

\section{REFERENCES}

Atwood, Margaret (1972) Survival: A Thematic Guide to Canadian Literature. Toronto, Canada, McClelland \& Stewart.

Ahenakew, Freda (1988) How the Mouse Got Brown Teeth: A Cree Story for Children. Illus. George Littlechild. Saskatoon, Canada, Fifth House Publishers.

Bannatyne-Cugnet, Jo (2000) From Far and Wide: A Citizenship Scrapbook. Illus. S.N. Zhang. Toronto, Canada, Tundra Books.
Bannerji, Himani (2000) The Dark Side of the Nation: Essays on Multiculturalism, Nationalism and Gender. Toronto, Canada, Canadian Scholars' Press.

Bhabha, Homi (1994) The Location of Culture. New York, Routledge.

Beynon, June (2004) From Teacher to Teacher Educator: Collaboration Within a Community of Practice. Vancouver, Canada, Pacific Educational Press.

Bouchard, David (1993) If You're Not From the Prairie. Vancouver, Canada, Raincoast Books \& Summer Wild Productions.

Bradford, Clare (2007) Unsettling Narratives: Postcolonial Readings of Children's Literature. Waterloo, ON, Wilfred Laurier Press.

Britzman, Deborah (1991) Practice Makes Practice: A Critical Study of Learning to Teach. Albany, State University of New York Press.

Carson, Terrance, \& Ingrid Johnston (2002) 'The difficulty with difference in teacher education: toward a pedagogy of compassion', The Alberta Journal of Educational Research XLVI, 1: 75-83.

Fitch, Sheree (2001) No Two Snowflakes. Victoria, Canada, Orca Book Publishers.

Highway, Tomson (2001) Caribou Song. Illus. B.Deines. Toronto, Harper Collins Publishers.

King, Thomas (1992) A Coyote Columbus story. Illus. William Kent Monkman. Toronto, Douglas \& McIntyre.

Kusugak, Michael (1990) Baseball Bats for Christmas. Toronto, Annick Press.

Laurence, Margaret (1989) 'Where the world began', in Margaret Iveson, John E. Oster \& Jill McClay (eds) Literary Experiences. Volume 1. Canada, Prentice Hall Ginn, pp.252-257.

Major, Kevin (2000) Eh? to Zed. Illus. A. Daniel. Red Deer, Red Deer College Press. 